\title{
Analysis Of Mathematical Representation By React Strategy On The Realistic Mathematics Education
}

\author{
Supandi $^{1 *}$, St. Budi Waluya ${ }^{2}, \operatorname{Rochmad}^{2}$ \\ ${ }^{1}$ Universitas PGRI Semarang, Semarang, Indonesia \\ ${ }^{2}$ Semarang State University, Semarang, Indonesia
}

This study was aimed to analyze the ability of mathematical representations in the eighth-grade junior high school students by using the REACT strategy on the learning of Realistic Mathematics Education (RME). The REACT strategies represent Relating, Experiencing, Applying, Cooperating, and Transferring. This study was a quasiexperimental research with nonrandomized pretest-posttest control group design. The population of this study was students in the eighth grade. Two classes were selected and classified as a class of experiments (with RME approach by REACT strategy), and control class (with scientific approach). Data obtained was analyzed by the independent t-test and proportions test. The results showed that there was an interaction between the approaches of RME with REACT strategy on the ability of mathematical representation. The students with approach RME by REACT strategy had better representation ability than the students with current approach scientific. In addition, it was found that more than seventy percent of students with RME approach by REACT strategy fulfill the learning completeness.

Keywords: representation, mathematics, strategy, REACT, RME, problem-solving

*Corresponding author email: hspandi@gmail.com; supandi@upgris.ac.id 


\section{Introduction}

The ideas of representation in the mathematics teaching and learning have developed in recent years, through the contributions of researchers and practitioners (NCTM, 2001). The representation ideas have broadly related to mathematics, the psychology of learning mathematics and problem solving, the growth of children mathematics and development, classroom teaching mathematics. It was found that the technology environment changed rapidly when the mathematics education took place (Goldin \& Janvier 1998a, 1998b; Goldin \& Kaput 1996). Representation is more than a process. It is a way of teaching and learning mathematics. Mathematical ideas can be represented in a various form such as drawings, concrete materials, tables, charts, numbers and letter symbols, as well as spreadsheets. The form of mathematical ideas representation was the basis of how people understand and use their ideas. Nowadays, the example of representation mathematics is a result of culture process improvement for years. When students have access to mathematical representations, express the ideas and can produce representations to capture mathematical concepts or relationships, they obtain a set of tools that significantly expand their capacity as a model and interpret physical phenomena, social, and mathematics (NCTM, 2000).

Representations can be applied by teachers to understand the enhanced role of High Order Thinking Skills (HOTS) in empowering students to convert into a higher level of cognitive functioning. The context of cognitive functioning was to overcome the questions and demanding tasks. Analysis and model provided an important starting point for the design of future professional development program for mathematics teachers (Mohd, et al., 2016). The applied words and symbols to communicate did not refer directly to the realism. However, those applied for represented entities by objects, properties, relationships, processes, actions, and construction, where there was no automatic agreement between two people. This was a process connecting between the original analysis of action role in the representation (Vergnaud, 1998). The figures prevailing in the writing of mathematics were formal and impersonal, reflecting the views of absolute mathematical properties for supporting students since they learn to write their own investigative work report (Morgan, 2014). Andrá, et al. (2015) showed that there was significant differences in eye movement between equations and graphs. This difference was realized in terms of the cultural shaping and social aspects of human perception, as well as in terms of the difference between symbolic and graphic registers.

The ability of representation had less attention in the learning process even though the representation ability could support another competence in mathematics. Representation had an important role in improving the understanding of mathematical concepts and student mathematical problem-solving. Research related to the students in this domain 
had improved, while research related to the teacher was less developed (Bannister, 2014). However, a study by Minarni, et al. (2016) of mathematical understanding development and students ability representation found that student achievement in mathematical understanding and representation test was in a low category.

Realistic Mathematics Education is a learning approach focused on the real problem is known and experienced by students and can also be imagined by the students as the starting point of learning. Realistic Mathematics Education was a method starting from the idea of learning and teaching to illustrate by using an example of basic illustrations. Moreover, learning strategy has an important role in the learning process. The approach supplemented with good strategy results on meaningful learning. Hence, a mathematical learning strategy was required in order to improve the students' ability of mathematical representations.

One of the alternative learning strategies application is contextual learning through REACT strategy. The REACT was introduced by the Center for Occupational Research and Development (CORD, 2017). According to Crawford \& Witte (1999), this strategy involved five elements consisting of Relating, Experiencing, Applying, Cooperating, and Transferring. The five aspects of REACT were a unity in the learning implementation comprising "involving" (Relating), "perform a search and investigations" (Experiencing), "the application of problem-solving" (Applying), "cooperate and share" (Cooperating), and "to transfer knowledge" (Transferring). Learning with REACT strategy is initiated by giving motivation to the students. Teachers motivate the students by linking the learning materials with their acquired knowledge (either from school or from the environment around them) so the students can understand the concept easily. Students are given the opportunity to have experience in the process of concept invention of the studied material by solving problems or doing any activities provided in the students' worksheets. The obtained concept is then used to solve the problem. By familiarization of carrying out the activity, this will enhance the students understanding of the concept.

\section{METHOD}

\section{Research Design}

In this research, the quasi-experimental research was applied. Specifically, the nonrandomized pre-test-post-test control group design was selected for the quasiexperimental research. The non-randomized pre-test and post-test control group were designed by providing pre-test and post-test in order to determine the initial state of the subjects before the study without randomization of a control class and experimental class. The subject of this research was the eight-grade class with the topic of relation and function. The sample group comprised two eight-grade classes with 74 students. The 
group was randomly divided into the experiment group (consist of 38 students) and control group (consist of 36 students). In the experimental group, the RME approach with REACT strategy was applied. On the contrary, the control group was appointed as a group with scientific approach applied.

At the beginning and at the end of the lesson, students at the experimental and control class were given the initial and final test. Those tests evaluated the ability of a mathematical representation. The test instrument in this study was an analysis question consisting of 6 queries with course subject of relations and functions. The analysis questions were used to determine the ability of students' mathematical representation including aspects of drawing, mathematic expression, and written text. The tests were provided to both classes at the beginning and end of the lesson.

\section{Data Analysis}

Before testing the hypothesis, the data was analyzed with a statistical test for normality by using the Shapiro-Wilk test and homogeneity of variance by using Levene statistics (Statistical Package for Social Science or SPSS). Evaluation of each question of the ability of students' mathematical representations has been determined based on the scoring rubric. Data of capabilities mathematical representation obtained through measurements with test instruments were converted to values in the range of 0 to 100 . The scores were then classified into a minimum completeness criteria based on school criteria for mathematics courses (the score was 70).

Furthermore, the effect of treatment on the experimental class was determined by using test Independent Sample Test. Criteria of decisions were decided based on the obtained $\mathrm{t}$-calculation analysis compared to the $\mathrm{t}$-table at a significance level of 5 percent. Then, the table Group Statistics was used to find out the higher average class. The test of proportion was applied to determine the completeness of students in the experimental class and control class. Criteria of decisions were ascertained based on the obtained zcalculation analysis compared to the z-table at a significance level of 5 percent.

\section{FINDINGS}

Test for normality and homogeneity of variance test data showed that the data were normally distributed and homogeneous, then the further test of Independent Sample Test was followed. Based on the results (output) section of independent sample test, it was found that for Levene Test, F value was 0.257 with the significance of 0.614 . Since the significance value was more than 0.05 , the null hypothesis was accepted. Hence, the second variant was identical populations. Due to both variants of the population were 
identical, determination of t-calculation table using independent sample test base variant Equal was assumed. The obtained $t$ count was -2.888 with value significance for twotailed, namely 0.005 . The value of $\mathrm{t}$-table was 2.03011 and the $\mathrm{t}$-count was -2.888 , then premises of the null hypothesis was rejected. Based on the value of significance, a significance value obtained two - tailed was 0.005 , and the null hypothesis was rejected. So it was found that both the average population was not identical. The difference of output is shown in Table 1.

Table 1

The average value of post-test

\begin{tabular}{|c|c|c|c|c|c|c|}
\hline & Class & $\mathrm{N}$ & Mean & $\begin{array}{c}\text { Std. } \\
\text { Deviation }\end{array}$ & $\begin{array}{l}\text { Std. } \\
\text { Mean }\end{array}$ & Error \\
\hline \multirow[t]{2}{*}{ Posttest } & Control & 36 & 62.28 & 17.389 & & 2.898 \\
\hline & Experiment & 36 & 73.75 & 16.300 & & 2.717 \\
\hline
\end{tabular}

Based on the Statistic in Table 1, it is obtained an average value post-test control class of 62.28, and the average value of post-test experimental class students of 73.75. This shows that the average value of post-test of students in the experimental class is higher than the value of the students in the classroom post-test control.

The significant difference between the results of the post-test control class and experimental class students caused by different steps in the learning process. Lessons are conducted by teachers of experimental class always put the realities and experiences of students as the initial starting point of learning. Through the presentation of contextual questions, students can see, hold or imagined objects they encounter in everyday life. This could provide special meaning for students. In this research, the problem for the students was well-known questions, hence this helped students to translate these questions into the language, symbols, and notations of their own making.

The further test was carried out to determine if the proportion is more than 70 percent of students in the class by Realistic Mathematic Education approach with REACT strategy fulfill the learning completeness. Before the test by proportions, the individual and classical learning completeness were determined. The proportion test of experimental class is displayed in Table 2 .

Table 2.

Proportion Test

\begin{tabular}{llllll}
\hline $\begin{array}{l}\text { Proportion } \\
\text { completeness } \\
\text { Individuals }\end{array}$ & $\begin{array}{l}\text { Percentage } \\
\text { Complete }\end{array}$ & Significance & $-Z_{\alpha}$ & $Z_{\text {obs }}$ & Criteria \\
\hline 0,72 & 0,7 & 0,05 & $-1,645$ & 0,29 & Complete \\
\hline
\end{tabular}


According to Table $2, Z_{\text {obs }} 0.29$ with a significance level of 0.05 with $-Z_{\alpha}$ is -1.645 are obtained. Since $Z_{\mathrm{obs}}$ over $-\mathrm{Z} \alpha(0.29>-1.645)$, then the null hypothesis is rejected and the alternative hypothesis is accepted. This shows that the percentage of students who complete their study has reached more than 70 percent. In general, the mathematical representation ability scores in the experimental class is superior to the control class. This is supported by the answer to the representation in the sample question. Figure 1 displays the sample question of drawing representation ability.

"In the eighth-grade junior high school, there is a study group comprised four people, namely Ani, Adi, Ina, and Iman. Ani has a brother called Bob. Adi has two sisters called Surya and Hani. Ina does not have any sister. While Santi is the sister of Iman. Describe the relationship of "sister of" from the story above all in the form of an arrow diagram, Cartesian coordinates, and the pair set sequence"

Figure 1. Sample Question of Drawing Representation Ability

It is found that the ability increase of the mathematical representation of students after learning through using RME approach by REACT strategy had positively impact on the student achievement. With the increase of student representation, the student achievement is improved. This is evident from the proportion of test results showing that more than 70 percent of students fulfill the learning completeness. The differences of student responses for the control class and the experimental class in drawing indicator is shown in Figure 2 and Figure 3, respectively. The indicator of drawing representation presents the student's ability to express the relation in the form of an arrow diagram, Cartesian coordinates, and a set of sequential pairs. 


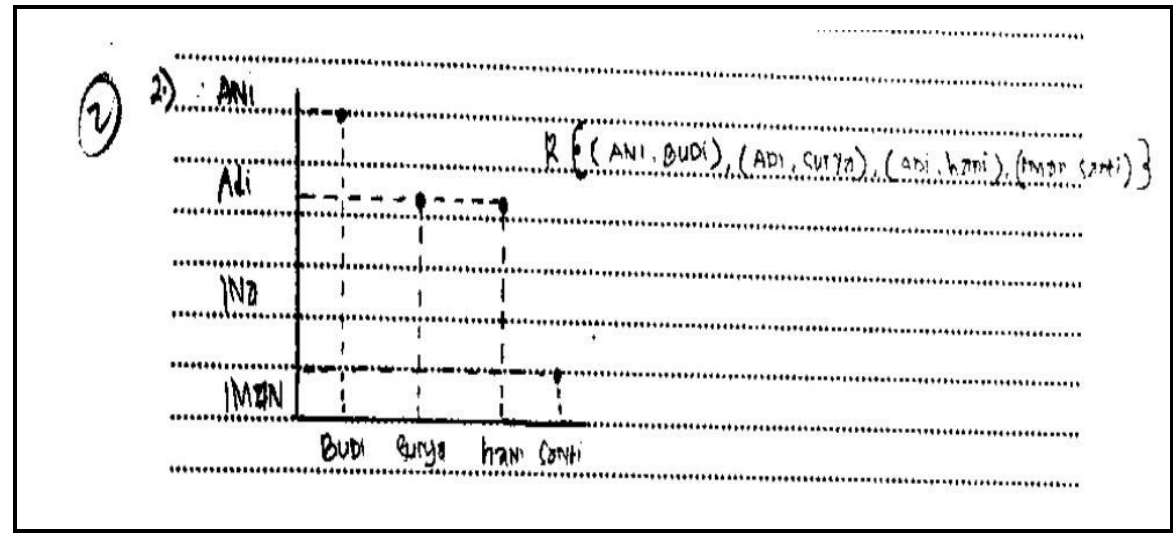

Figure 2. Indicator of Drawing Representation (Score 2) in the Control Class

Representation indicator as displayed in Figure 2 shows that the student is able to illustrate the arrow diagram, Cartesian coordinates, and the set of a sequential pair of illustrations in the given problem. However, the illustrations are not represented perfectly. Students are only able to describe Cartesian diagram and the results are unsatisfactory. In addition to the set of consecutive pairs, the students have not been able to determine it correctly.

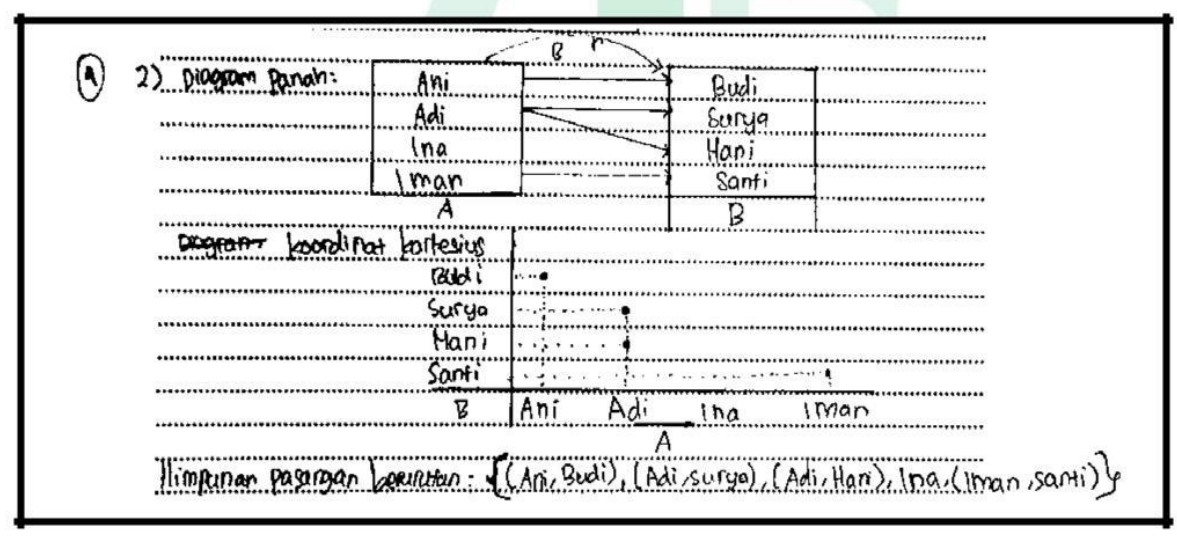

Figure 3. Indicator of Drawing Representation (Score 4) in the Experiment Class

Representation indicator of experiment class is presented in Figure 3. It is found that the student is able to represent the arrow diagram, Cartesian coordinates, and the set of a sequential pair of given question. The Arrow diagrams and Cartesian coordinates are 
described completely and correctly and the set of the sequential pair is described appropriately. This answer obtained the maximum score of 4 in accordance with the guidelines of scoring.

The question of expression mathematic representation ability and a sample of student answer in experiment class are presented in Figure 4 and Figure 5, respectively.

Given a rectangular coordinate that shows the relations "exercise" as the following:

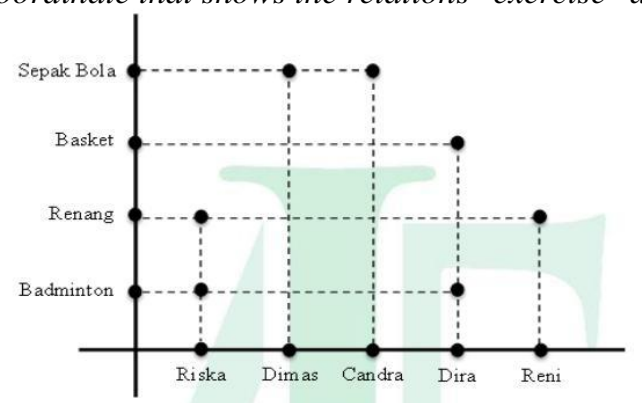

Figure 4. Question of expression mathematic representation ability

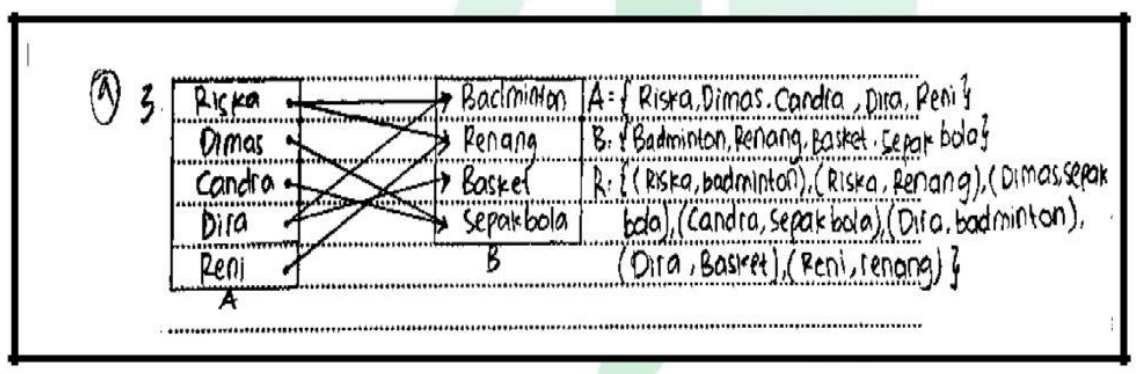

Figure 5. Sample Answer of Mathematic Expression Representation in the Experiments Class (Score 4)

Figure 5 illustrates that students are able to determine the Cartesian coordinates as given in the question and to represent in the form of arrows and diagrams as well as the set of sequential pairs. The arrow diagram depicted completely and correctly. In addition, the set of sequential pairs is correctly determined, including the use notation such as the name of the set and punctuation as equals, commas, and parentheses. The answer obtained a score of 4 in accordance with the guidelines for scoring. The score of 
4 is quantitatively categorized as 'the student is competent to determine a complete and accurate mathematical model'.

The representation, as displayed in Figure 6, shows that the students have been able to determine the Cartesian coordinates on a given problem and represent in the form of arrows and diagrams as well as the set of sequential pairs. The arrow diagram is depicted correctly, but incompletely. The set of pairs sequentially is determined correctly, however, an error in the use of punctuation is found. The answer obtained a score of 3 in accordance with the guidelines of scoring. The score is quantitatively categorized as 'the student is able to write a mathematical model precisely but less completed'.

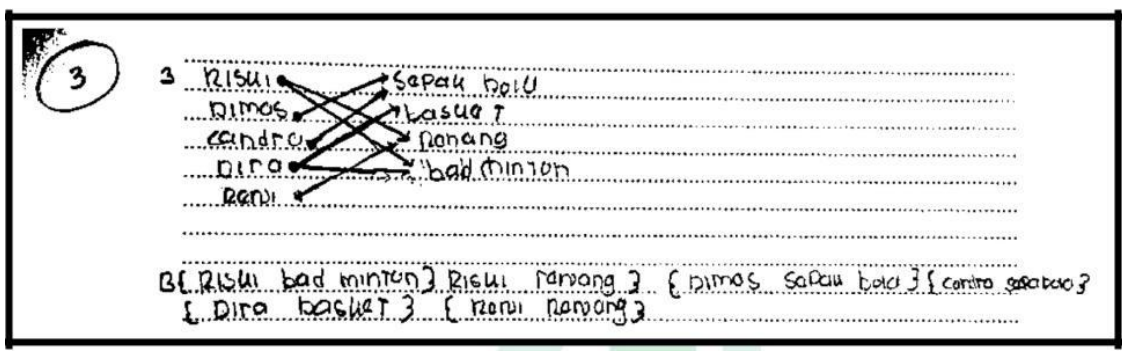

Figure 6. Sample Answer of Mathematic Expression Representation in Class Experiment (Score 3)

According to each indicator of mathematical representation, the experimental class was superior to the control class. The percentages are shown in Table 3 below.

Table 3

Indicators of Percentage Achievement in Mathematical Representation

\begin{tabular}{ccc}
\hline Indicator & Class Control & Class Experiment \\
\hline Drawing & $64 \%$ & $80 \%$, \\
Mathematics Expressions & $55 \%$ & $72 \%$ \\
Written Text & $71 \%$. & $58 \%$. \\
\hline
\end{tabular}

Table 3 shows the percentage of achievement indicators of representation class for the control and experimental classes. For the visual representation, the achievement percentage the ability representation of the control class is 64 percent and the experimental class is 80 percent. In the representation of mathematical expressions, the percentage of representation ability achievement in the control and experimental class are 55 percent 72 percent, respectively. For the representation of written texts, the percentage of representation ability achievement in the control class is 71 percent and the experimental class is found as 58 percent. 


\section{CONCLUSION, DISCUSSION, and SUGGESTIONS}

Implementation of learning with REACT strategy is able to improve the mathematical representation of students in the experimental class. This is resulted due to the stages of learning by the REACT strategy provided easier understanding for students and intensify their understanding of a concept. The REACT strategy had some advantages such can enhance students' understanding, to generate a complete study and a pleasant learning process.

The REACT strategy assisted teachers to create student-centered learning. Learning steps lead students to actively understand the concept of the trial subject studied. In addition, students were also guided to express their opinions, for example giving an opinion in a small group and presenting the group's work in front of his classmates. This made the learning developed into more significant since the students found their own understanding.

In the relating stage, the students are guided to understand the subject of studied by connecting them with past experience or comprehension. Then the subject is also related to the daily life, hence that students are easy to understand. Furthermore, at the stage of experiencing and cooperating, the students discovered new concepts by working in groups. Students were given the opportunity to discuss and to express their ideas as well as to give feedback in order to obtain a conclusion of the concept.

The obtained concept at the stage of experiencing and cooperating was then applied to resolve provided problems or questions. This activity was a form of realization in the stages of applying and transferring. At this stage, students were guided to determine applicable concept to solve simple or complex problems. By this familiarization, the student understanding was more persistent and improve the representation ability.

Learning by the Realistic Mathematics Education (RME) approach with REACT strategy affected the ability of students' mathematical representation. The RME approach learning with REACT strategy was able to improve the student representation. In general, the experimental class students obtained a higher score than the control class. The completeness learning of individual students using RME approach by REACT strategy was over seventy percent. The ability of a mathematical representation of students on the course subject of relations and functions using RME approach by REACT strategy provided a mathematical representation capabilities better than the scientific approach. This finding was supported by Utami et.al (2016) showed that the 
application of REACT strategy in Geography was effective in developing student skills of Geography. In addition, it was concluded that learning using REACT was recommended to be applied in mathematics teaching (Rohayati, 2013). However, the REACT strategy required several adjustments such as adding some new stages or extending some stages content (Ultay, 2012). Furthermore, it was found that the learning by using the RME approach with REACT strategy took relatively longer than the learning by the scientific approach. Therefore, it is suggested for further research that when the REACT strategy is applied, the appropriate materials should be selected and hence the learning mathematics will be more effective.

\section{REFERENCES}

Andrá, C., Lindström, P., Arzarello, F. et al., (2015), Reading Mathematics Representations: An Eyetracking Study, International Journal of Science And Mathematics Education, 13(Suppl 2): 237. doi:10.1007/s10763-013-9484-y

Bannister, V.R.P. (2014), Flexible Conceptions of Perspectives and Representations: An Examination of Pre-Service Mathematics Teachers' Knowledge, International Journal of Education in Mathematics, Science and Technology, 2( 3), July 2014, 223233

CORD, (2017). REACTing to Learn: Student Engagement Strategies in Contextual Teaching and Learning, CORD Leading Change in Education, (retired 13 February 2017, from http://www.cord.org/REACTflyer_website.pdf)

Crawford, M., \& Witte, M., (1999). "Strategies for Mathematics: Teaching in Context," Educational Leadership 57(3):34-38.

Goldin, G.A., \& Janvier, C., (1998a). "Representations and the Psychology of Mathematics Education, Part L." (Special Issue) Journal of Mathematical Behavior, 17( I), $1-134$

Goldin, G.A., \& Janvier, C. (1998b). "Representations and the Psychology of Mathematics Education, Part IL" (Special Issue) Journal o Mathematical Behavior, 17( 2), 135-301.

Goldin, G.A., \& Kaput, J.J., (1996). "A Joint Perspective on the Idea of Representation in Learning and Doing Mathematics?' In Theories of Mathematical Learning, edited by Leslie P. Steffe, Pearla Nesher, Paul Cobb, Gerald A. Goldin, and Brian Greer, pp. 397430. Hillsdale, N.J.: Lawrence Erlbaum Associates 
Minarni, A., Napitupulu,E.E., Husein, R., (2016). Mathematical Understanding And Representation Ability Of Public Junior High School In North Sumatra. Journal on Mathematics Education, 7(1), 45-58

Mohd, N., Tajudin, Chinnappan, M., (2016). The Link between Higher Order Thinking Concepts in Enhancing TIMSS Tasks. International Journal of Instruction, 9(2)

Morgan, C., (2014). Mathematics And Human Activity: Representation In Mathematical Writing, Research in Mathematics Education. Institute of Education, University of London, Published online: 14 Apr 2008. This article was downloaded by: [Northeastern University], On: 14 October 2014, At: 14:20

NCTM, (2000). Principles and Standards for School Mathematics. United States of America: Reston, VA.

NCTM, (2001). Roles for Representations in School Mathematics, 2001 Yearbook.

Rohayati, T., (2013). The Implementation of Contextualization in Teaching Vocabulary to Elementary Students (REACT: Relating, Experiencing, Applying, Cooperating, And Transferring). Journal of English and Education, 1(2), 115-123

Ultay, E., (2012). Implementing REACT Strategy In A Context-Based Physics Class: Impulse And Momentum Example. Energy Education Science and Technology Part B: Social and Educational Studies, 4(1), 233-240.

Utami, W. S., Sumarmi, Ruja, I N., Utaya, S., (2016). React (Relating, Experiencing, Applying, Cooperative, Transferring) Strategy to Develop Geography Skills. Journal of Education and Practice, 7(17), 100-104.

Vergnaud, G., (1998). A Comprehensive Theory Of Representation For Mathematics Education. Journal of Mathematical Behavior, 17(2), 167-181 